\title{
Disease Progression and the Application of Evidence-Based Treatment Guidelines Diagnose It Early: A Case for Screening and Appropriate Management
}

\author{
Harold J. Manley, PharmD, FASN, FCCP, BCPS
}

\begin{abstract}
BACKGROUND: Screening processes to identify patients who have chronic kidney disease (CKD) early in the disease allow time to manage its comorbidities and complications effectively and aggressively. The Kidney Early Evaluation Program (KEEP), sponsored by the National Kidney Foundation (NKF), is a free screening program that targets people who have diabetes, hypertension, and parents, grandparents, or siblings with diabetes, hypertension, or CKD.

OBJECTIVES: To (1) introduce KEEP and its objectives and (2) review population data and progress with goals to date.

SUMMARY: The KEEP goals are to raise awareness of CKD, especially in high-risk patients, provide free testing, and encourage dialogue between patients and their physicians, leading to a treatment plan. Of the 55,000 patients who have been screened through KEEP, approximately $13,000(29 \%)$, or nearly 1 in 3 patients, have been identified as having CKD. Once a patient has been diagnosed with CKD, clinicians must address risk factors such as diabetes, hypertension, and kidney-specific diseases (e.g., glomerular diseases) that contribute to the process of renal decline. The NKF through the Kidney Disease Outcomes Quality Initiative has assembled a series of guidelines addressing dialysis adequacy, vascular access, anemia, nutrition, CKD, bone and mineral metabolism, dyslipidemia, hypertension, cardiovascular disease, and diabetes.

CONCLUSION: CKD is quite common but often unrecognized and undertreated, even though rigorous guidelines for diagnosis and care have been developed. Ten areas have been identified as important for optimal care of the CKD patient. Each of these areas should be addressed and closely monitored in this population: hypertension, anemia, glucose control, lipid control, smoking cessation, aspirin prophylaxis and use of a beta-blocker post-myocardial infarction, use of angiotensin-converting enzyme inhibitors or angiotensin II receptor blockers, diet, exercise, and weight control.
\end{abstract}

J Manag Care Pharm. 2007:13(9):S6-S12

Copyright $\odot$ 2007, Academy of Managed Care Pharmacy. All rights reserved.

\section{Author}

HAROLD J. MANLEY, PharmD, FASN, FCCP, BCPS, is director, clinical pharmacy, VillageHealth Disease Management, Glenmont, New York.

AUTHOR CORRESPONDENCE: Harold J. Manley, PharmD,

Director, Clinical Pharmacy, VillageHealth Disease Management, 16 Vagele Lane, Glenmont, NY 12077. Tel.: 518.932.4416;

E-mail: harold.manley@villagehealth.com
The Kidney Early Evaluation Program (KEEP), sponsored by the National Kidney Foundation (NKF), is a free screening program that targets people who have diabetes, high blood pressure, and parents, grandparents, or siblings with diabetes, hypertension, or chronic kidney disease (CKD). ${ }^{1}$ Patients can refer themselves after learning about KEEP from magazines, newspaper articles, or other media, or can be referred by a health care provider. Although KEEP is administered by the NKF, the actual screening events are organized by $52 \mathrm{NKF}$ affiliates. KEEP is staffed by lay and professional volunteers who are trained by the NKF. The program's goals are to raise awareness of CKD, especially in highrisk patients; provide free testing; and encourage dialogue between patients and their physicians, leading to a treatment plan. Educating and empowering patients is also a goal in order to prevent or delay CKD, initiate appropriate referrals for follow-up care, and provide ongoing information and support. ${ }^{1}$

During a KEEP screening, volunteer health care professionals (e.g., physicians, nurses, and pharmacists) monitor blood pressure, record weight, and coordinate lab work (e.g., blood glucose, hemoglobin, urine dipstick for microalbuminemia and hematuria, albumin, and serum creatinine). Albumin to creatinine ratio is employed to determine serum creatinine and estimate glomerular filtration rate (eGFR) using a Modification of Diet in Renal Disease equation. Clinicians notify patients of the screening results and may refer them to their primary care physicians for follow-up if abnormal results were identified.

Abnormal results identified during a KEEP screening are not considered diagnostic but rather, indicative of increased risk. Overall, patient participation in the KEEP screening process takes approximately 30 minutes. At the conclusion of the screening, the clinician sends data collected to the NKF. ${ }^{1}$ Aggregate data are published yearly in the KEEP Annual Data Report. Of the 55,000 patients who have been screened through the KEEP process since its inception in 2000, approximately 13,000 (29\%), or nearly 1 in 3 patients, have been identified as having CKD, with stage 3 being identified most frequently. ${ }^{2}$

\section{CKD: Progression and Comorbidities}

Once a patient has been diagnosed with CKD, clinicians must identify and address risk factors associated with disease progression. Risk factors may be divided into 3 descriptive categories:

1. Susceptibility factors, such as advanced age, racial/ethnic minorities, family history, and low income or education, may put a patient at an increased risk of developing CKD. For example, approximately 50 million Americans are more than 60 years old and should be monitored for progressive renal function decline. ${ }^{2}$ Thirty-four million black Americans and 35 million Hispanics or Latinos are also at increased risk for CKD. ${ }^{2}$ 


\section{Disease Progression and the Application of Evidence-Based Treatment Guidelines}

Diagnose It Early: A Case for Screening and Appropriate Management

2. Initiators are factors such as diabetes, hypertension, and kidney-specific diseases (e.g., glomerular diseases) that are strongly associated with the beginning of renal decline.

3. Progression factors contribute to the advancement of CKD and include hyperglycemia, hypertension, proteinuria, and smoking. ${ }^{2}$ Each of these factors is modifiable through patient behaviors and drug therapy. Addressing them is critical. Diabetes is the primary cause of end-stage renal disease (ESRD). However, the presence of hypertension is also a strong risk factor and is more common, affecting 43 million Americans. ${ }^{2}$ Most often, diabetes and hypertension are comorbid and must both be addressed and managed.

Evaluation includes diagnosing the underlying cause of $\mathrm{CKD}$, staging for severity, identifying comorbid conditions and complications, and assessing risk of cardiovascular disease (CVD). The results of evaluation should drive specific therapy (see Table 1) with an overall goal of preventing further loss of kidney function. Glomerular disease should be treated, if possible, and if diabetes and/or hypertension are present, controlling glycosylated hemoglobin (Alc) and blood pressure is crucial. Early detection and aggressive management of CKD and its comorbidities may slow or arrest progression to ESRD. Employing medications that may reduce glucose or blood pressure and simultaneously reduce proteinuria; prescribing an erythropoiesis-stimulating agent (ESA) and/or an iron product for anemia; starting a lipid-lowering product; and using primary prevention medications such as aspirin are part of the CKD management principles.

Medication review is critical for patients who have CKD. There are several areas where patients require guidance or where medications require adjustment. Renally cleared medications often require dosage adjustment as kidneys fail and some medications accumulate, making them more difficult to use. It may be necessary to increase therapeutic drug monitoring and a host of new medications may need to be added. New medications added as renal decline progresses must be compatible with the current regimen. A patient with stage 3 or 4 CKD is prescribed an average of 6 to 8 medications. ${ }^{3} \mathrm{~A}$ patient at end-stage CKD is prescribed about 10 to 12 medications. ${ }^{4}$ Therapeutic drug monitoring should prevent most drug-drug interactions and some adverse drug events, while patient education may help to make adverse events more manageable for the patient and provide continual encouragement for patient adherence to the treatment regimen.

\section{Kidney Disease Outcomes Quality Initiative Guidelines}

The CKD patient population tends to experience a number of adverse outcomes and comorbidities, and the NKF has attempted to help clinicians address these concerns. The Kidney Disease Outcomes Quality Initiative (KDOQI), developed by a multidisciplinary team, was created to provide comprehensive diagnosis and management guidelines for CKD. ${ }^{5}$ Within

\section{TABLE $1 \longdiv { \text { Management Principles for CKD } }$}

\begin{tabular}{|c|c|}
\hline $\begin{array}{l}\text { Delay or } \\
\text { stop CKD } \\
\text { progression }\end{array}$ & $\begin{array}{l}\text { - Treat underlying conditions if possible. } \\
\text { - Address blood pressure control, aggressively targeting } \\
\text { JNC 7's target values. } \\
\text { - Use ACEIs as tolerated, monitoring for renal } \\
\text { deterioration and hyperkalemia. } \\
\text { - Follow the American Diabetes Association } \\
\text { recommendations for glycemic control (target Alc <7\%). } \\
\text { - Consider protein restriction. } \\
\text { - Treat hyperlipidemia. } \\
\text { - Avoid nephrotoxins (nonsteroidal anti-inflammatory } \\
\text { agents, aminoglycosides). }\end{array}$ \\
\hline $\begin{array}{l}\text { Treat CKD's } \\
\text { pathologic } \\
\text { manifestations }\end{array}$ & $\begin{array}{l}\text { - Anemia (erythropoietin-stimulating agents) } \\
\text { - Hyperphosphatemia (dietary phosphate binders and } \\
\text { dietary phosphate restriction) } \\
\text { - Hypocalcemia (calcium supplements and/or calcitriol) } \\
\text { - Hyperparathyroidism (calcitriol or vitamin D analogs) } \\
\text { - Volume overload (loop diuretics or ultrafiltration) } \\
\text { - Metabolic acidosis (oral alkali supplementation) } \\
\text { - Uremic manifestations with chronic renal replacement } \\
\text { therapy (hemodialysis, peritoneal dialysis, or renal } \\
\text { transplantation) } \\
\text { - Cardiovascular complications using standard of care }\end{array}$ \\
\hline $\begin{array}{l}\text { Plan for } \\
\text { chronic renal } \\
\text { replacement } \\
\text { therapy }\end{array}$ & $\begin{array}{l}\text { - Educate patients early and frequently about disease } \\
\text { progression, potential dialysis modalities, renal } \\
\text { transplantation, and the option to refuse or discontinue } \\
\text { chronic dialysis. } \\
\text { - Place permanent vascular access (arteriovenous fistula) } \\
\text { at least } 6 \text { months in advance of anticipated date of } \\
\text { dialysis. } \\
\text { - Arrange elective peritoneal dialysis catheter insertion. } \\
\text { - Refer for renal transplantation early. }\end{array}$ \\
\hline $\begin{array}{l}\text { Establish } \\
\text { a multi- } \\
\text { disciplinary } \\
\text { team early }\end{array}$ & $\begin{array}{l}\text { - Refer to nephrology early. } \\
\text { - Involve a renal dietitian. } \\
\text { - Schedule vascular surgery for permanent vascular } \\
\text { access. } \\
\text { - Schedule general surgery for peritoneal catheter } \\
\text { placement. } \\
\text { - Enroll the patient in a renal transplant center. }\end{array}$ \\
\hline $\begin{array}{l}\text { Address } \\
\text { dietary } \\
\text { changes }\end{array}$ & $\begin{array}{l}\text { - Restrict protein as the patient approaches CKD stage } 5 \text { to } \\
\text { delay onset of uremic symptoms. } \\
\text { - Assess malnutrition risk and implement strategies } \\
\text { to correct or address it. } \\
\text { - Restrict phosphate, starting early in CKD. } \\
\text { - Restrict potassium. } \\
\text { - Restrict sodium and water as necessary to avoid } \\
\text { volume overload. }\end{array}$ \\
\hline
\end{tabular}

References 1 through 9 were used to develop this chart.

$A C E I=$ angiotensin-converting enzyme inhibitor; $C K D=$ chronic kidney disease;

JNC $7=$ Seventh Report of the Joint National Committee on Prevention, Detection, Evaluation, and Treatment of High Blood Pressure. 


\section{FIGURE 1 Association of Level of GFR With Complications}

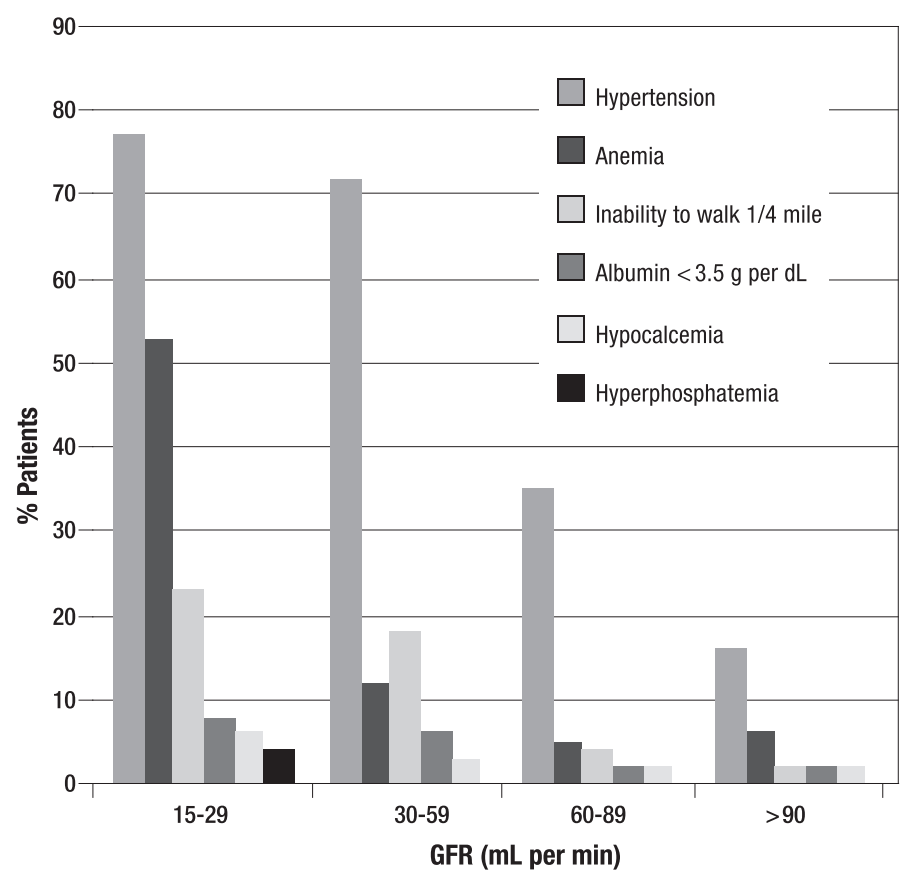

Adapted from K/DOQI Clinical Practice Guidelines for Chronic Kidney Disease Evaluation, Classification, and Stratification. Available at: www.kidney.org/ professionals/KDOQI/guidelines_ckd/toc.htm. Accessed on September 17, 2007. GFR=glomerular filtration rate

KDOQI, separate guidelines have been developed to address each of the following areas: dialysis adequacy, vascular access, anemia, nutrition, CKD, bone and mineral metabolism, dyslipidemia, hypertension, CVD, and diabetes. ${ }^{1}$ Although these diagnoses must be addressed in concert, each requires some specialized knowledge on the part of the clinician.

\section{Glomerular Filtration Rate}

Glomerular filtration rate (GFR), calculated from blood creatinine, age, race, gender, and other factors, is the best test measure to determine the degree of kidney dysfunction. A declining GFR is associated with additional complications, including anemia, inability to walk a quarter of a mile, low albumin (malnourishment), and electrolyte abnormalities (hypocalcemia and/or hyperphosphatemia) ${ }^{2}$ (Figure 1).

\section{Cardiovascular Disease}

Analysis of the Kaiser Permanente database has found that death rate correlates with declining GFR. ${ }^{6}$ Cardiovascular morbidity and mortality is greater among CKD patients than in the general population, and most patients with CKD will die of CVD before reaching ESRD. A 1999 study by Sarnak and Levey determined that the dialysis population, compared with the general population of people without $\mathrm{CKD}$, experiences a greater annual mortality rate related to cardiovascular events. ${ }^{7}$ In the general population, morbidity rates increase with age. For the dialysis population, risk is high from an early age and remains high. A 35- to 44-year-old dialysis patient, for example, has a cardiovascular risk comparable with that of an 84- or 85-year-old individual who is not on dialysis. CVD mortality rates are 15 times higher in the ESRD population than in people who do not have ESRD. All patients with CKD should be considered the highest risk group for CVD, and all CKD patients should undergo an assessment for traditional or CKD-related cardiovascular risk factors. Patients with CKD are at increased risk for CVD if they have traditional CVD risk factors, but additional risk factors specific to the CKD population can complicate their prognoses (Table 2).

The KDOQI treatment guidelines for CVD and hypertension emphasize that as GFR declines, the incidence of hypertension (defined as blood pressure $>140 / 90 \mathrm{~mm} \mathrm{Hg}$ ) increases from $42 \%$ in populations with normal GFR to approximately $75 \%$ in people with ESRD (GFR $<15 \mathrm{~mL}$ per minute per $1.73 \mathrm{~m}^{2}$ ). Bakris et al. conducted a meta-analysis examining mean arterial blood pressure and GFR decline. ${ }^{8}$ They found that as mean arterial blood pressure increases, GFR decline accelerates.

Reducing a blood pressure from $140 / 90 \mathrm{~mm} \mathrm{Hg}$ to 130/80 mm Hg can slow progressive renal disease. A blood pressure reduction of $10 \mathrm{~mm} \mathrm{Hg}$ can reduce renal disease progression by $65 \%$. For example, a 35 -year-old female with CKD and a serum creatinine of $1.5 \mathrm{mg}$ per $\mathrm{dL}$, an estimated GFR of $60 \mathrm{~mL}$ per minute per $1.73 \mathrm{~m}^{2}$, and a current blood pressure of 150/100 mg Hg could delay her progression to ESRD by 8 to 9 years by reducing blood pressure to $140 / 90 \mathrm{~mm} \mathrm{Hg}$. Further blood pressure reduction to 130/80 mm Hg could delay progression by 15 years. If, however, her blood pressure remains uncontrolled at 150/100 $\mathrm{mm} \mathrm{Hg}$, she can expect to need dialysis in 5 years. The importance of tight blood pressure control in CKD patients has also been identified by the Seventh Report of the Joint National Committee on Prevention, Detection, Evaluation, and Treatment of High Blood Pressure (JNC 7). ${ }^{9}$ This paradigm applies to all CKD patients in stages 1 through 4.

The average number of antihypertensive medications needed to control high blood pressure can be calculated, at least in the clinical setting, by looking at large antihypertensive trials. ${ }^{8,10}$ Most patients will require 3 or more medications to control blood pressure adequately. When choosing antihypertensive therapy for a patient with CKD, clinicians need to consider compelling comorbid indications, such as heart failure with systolic dysfunction, post-myocardial infarction with or without systolic dysfunction, chronic stable angina, high-risk coronary artery 
disease, recurrent stroke prevention, or supraventricular tachycardia. Depending on the comorbidities, certain antihypertensive medications are recommended for first-line use. Angiotensinconverting enzyme inhibitors (ACEIs) and angiotensin II receptor blockers (ARBs) are preferred in the diabetic and nondiabetic/ high protein excretion populations. No particular antihypertensive medication is preferred in the nondiabetic/low protein excretion and transplant populations. ${ }^{2}$ Both the KDOQI guidelines and JNC 7 recommend that clinicians prescribe the best agent for the patient's unique mix of comorbidities.

\section{Diabetes}

Diabetes, a CVD risk factor, also poses special challenges in the CKD patient. For each 1\% increase in Alc, the cardiovascular hazard ratio increases $15 \%$ in the patient with type 1 diabetes and $18 \%$ in the patient with type 2 diabetes. Three fourths of patients with diabetes die of CVD as opposed to one third of the general population. ${ }^{5}$ Steno et al. followed 160 type 2 diabetic patients with microalbuminuria for almost 8 years to determine if targeted, intensified, multifactorial intervention would lead to better outcomes than would conventional treatment. ${ }^{11}$ Study participants received either conventional therapy or intensive therapy. Intensive therapy stressed Alc control, employed aspirin therapy, and controlled lipids and blood pressure. In the intensive-therapy group, Alc values, systolic and diastolic blood pressure, serum cholesterol, and triglyceride levels were measured after an overnight fast. Findings included that the urinary albumin excretion rate declined to a greater extent than in the conventional-therapy group. Patients receiving intensive therapy reduced their risk of CVD by 53\%, nephropathy by $61 \%$, and retinopathy by $63 \%$. Target-driven, long-term, intensified intervention aimed at multiple risk factors in patients with type 2 diabetes and microalbuminuria reduces the incidence of $\mathrm{CKD}$ and prevents complications.

If a choice must be made between tight blood pressure control and tight glucose control in CKD patients, tight blood pressure control is more likely to reduce risk of stroke, any diabetic endpoint, diabetes mellitus death, or microvascular complications. ${ }^{8}$ Regardless, overall outcome will be better if all surrogate markers of CKD are addressed. ${ }^{7}$

\section{Anemia}

As kidney function declines during CKD progression from stage 1 to stage 5 , the risk of developing anemia increases dramatically (see Figure 2). ${ }^{12}$ Anemic patients with CKD usually have left ventricular hypertrophy, which may exacerbate heart failure. Furthermore, patients with CKD and anemia report reduced aerobic capacity, overall well-being, sexual function, and cognition. Body mechanisms, in attempting to fix or account for the damaged state caused by the triad of CKD, heart failure, and anemia, lead to a continuing promulgating cycle of worsening CKD, heart failure, and anemia. ${ }^{13}$

\section{TABLE 2 Traditional CVD Risk Factors and CKD-Specific CVD Risk Factors}

\begin{tabular}{l|l}
\hline Traditional CVD Risk Factors & CKD-Specific CVD Risk Factors \\
\hline Older age & Type of CKD \\
Male gender & Decreased GFR \\
White race & Proteinuria \\
Hypertension & RAS activity \\
Elevated LDL & ECF volume overload \\
Decreased HDL & Abnormal serum calcium \\
Diabetes mellitus & and phosphate \\
Tobacco use & Pronounced dyslipidemia \\
Physical inactivity & Anemia \\
Menopause & Malnutrition \\
Psychosocial stress & Inflammation \\
Family history of CVD & Infection \\
& Thrombogenic factors \\
& Elevated homocysteine \\
& Uremic toxins \\
\hline
\end{tabular}

National Kidney Foundation (2006). ${ }^{5}$

$C K D=$ chronic kidney disease $C V D=$ cardiovascular disease $E C F=$ extracellular fluid; GFR=glomerular filtration rate; $H D L=$ high-density lipoprotein;

$L D L=$ low-density lipoprotein; $R A S=$ renin-angiotensin system .

\section{FIGURE 2 Anemia Prevalence in CKD}

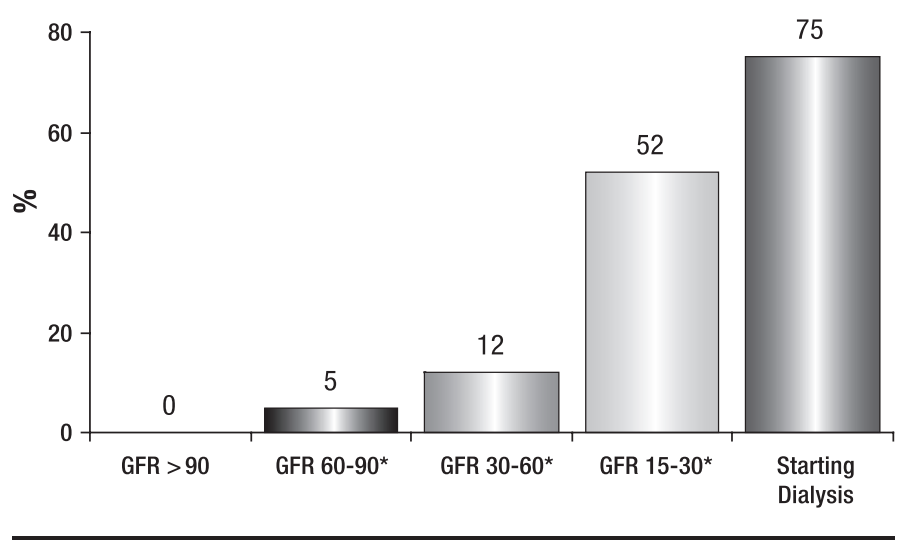

* Keane WF et al. ${ }^{12}$

** United States Renal Data System. USRDS 2005 Annual Data Report: Atlas of End-Stage Renal Disease in the United States. Bethesda, MD: National Institutes of Health, National Institute of Diabetes and Digestive and Kidney Diseases; 2005. $C K D=$ chronic kidney disease; $G F R=$ glomerular filtration rate.

The May 2006 KDOQI guidelines recommended a target hemoglobin of between 11 and $13 \mathrm{~g}$ per dL for anemia, but the April 2007 revision reduced the target range to 11 to $12 \mathrm{~g}$ per $\mathrm{dL} .{ }^{14}$ The KDOQI guidelines also recommend monitoring serum ferritin, transferrin saturation, and reticulocyte hemoglobin content for hemodialysis and peritoneal dialysis. To meet 


\section{Disease Progression and the Application of Evidence-Based Treatment Guidelines \\ Diagnose It Early: A Case for Screening and Appropriate Management}

KDOQI goals of a target hemoglobin of 11 to $12 \mathrm{~g}$ per dL, ESAs and oral or intravenous iron therapy are important pharmacologic therapies. ${ }^{15}$ With the recent black box warnings on ESAs emphasizing increased risk for death and serious cardiovascular reactions when administered to target a hemoglobin of $\geq 12$ g per $\mathrm{dL}$, dialysis organizations are examining their policies and adjusting algorithms.

In November 2006, 2 studies-CHOIR and CREATEwere published. The Correction of Anemia with Epoetin Alfa in Chronic Kidney Disease (CHOIR) included 1,432 patients with a mean GFR of $27 \mathrm{~mL}$ per minute per $1.73 \mathrm{~m}^{2} .{ }^{16}$ Of the study population, 715 patients were randomly assigned to receive a dose of epoetin alfa targeted to achieve a hemoglobin level of $13.5 \mathrm{~g}$ per $\mathrm{dL}$, and 717 received a dose targeted to achieve a level of $11.3 \mathrm{~g}$ per $\mathrm{dL}$. The groups attained average hemoglobin levels of $11.3 \mathrm{~g}$ per $\mathrm{dL}$ and $12.6 \mathrm{~g}$ per $\mathrm{dL}$, respectively, a difference of about $1 \mathrm{~g}$ per $\mathrm{dL}$, but the high-hemoglobin group required more erythropoietin to reach that level.

Two hundred twenty-two composite events occurred: 65 deaths (29.3\%), 101 hospitalizations for heart failure (45.5\%), 25 myocardial infarctions (11.3\%), and 23 strokes (10.4\%). Of these, 125 events occurred in the high-hemoglobin group and 97 events occurred in the low-hemoglobin group. Seven patients (3.2\%) were hospitalized for heart failure and myocardial infarction combined, and 1 patient $(0.5 \%)$ died after having a stroke. Improvements in quality of life were similar between the 2 groups. The probability of death was significantly less in the low-hemoglobin group. The use of a target hemoglobin level of $13.5 \mathrm{~g}$ per dL was associated with an increased risk of serious adverse events. ${ }^{16}$

Drueke et al. conducted a similar study, CREATE, (Cardiovascular Risk Reduction in Early Anemia Treatment with Epoetin Beta) to study whether correction of anemia in patients with stage 3 or 4 CKD improves cardiovascular outcomes. ${ }^{17}$ CKD patients with GFRs averaging $27 \mathrm{~mL}$ per minute per $1.73 \mathrm{~m}^{2}$ were randomized to ESA therapy to achieve a hemoglobin of 13 to $15 \mathrm{~g}$ per dL or 10.5 to $11.5 \mathrm{~g}$ per dL. Survival was similar between the groups over 48 months. One of the study conclusions was that early complete correction of anemia in CKD patients does not reduce the risk of cardiovascular events.

Other studies have examined hemoglobin's influence on outcomes. Besarab et al. studied more than 1,200 CKD patients receiving dialysis who were randomized to a normal hematocrit of $42+3 \%$ or a lower hematocrit of $30+3 \%$, equivalent to a hemoglobin of $12 \mathrm{~g}$ per $\mathrm{dL}$ and $10 \mathrm{~g}$ per $\mathrm{dL}$, respectively. ${ }^{18}$ After 29 months, patients in the normal-hematocrit group experienced 183 deaths and 19 first nonfatal myocardial infarctions. Those in the low-hematocrit group had 150 deaths and 14 nonfatal myocardial infarctions. The difference in event-free survival between the 2 groups did not reach the prespecified statistical stopping point, but the researchers halted the study early for safety concerns. Adequacy of dialysis declined for patients in the normal-hematocrit group, and they received more intravenous iron dextran than did low-hematocrit patients. The researchers concluded that hemodialysis patients with clinically evident heart failure or ischemic heart disease should be treated to lower hematocrit or hemoglobin targets.

In 2000, a KDOQI work group recommended targeting a hemoglobin concentration of 11 to $12 \mathrm{~g}$ per dL in CKD patients; they increased it to 11 to $13 \mathrm{~g}$ per $\mathrm{dL}$ in 2006. CHOIR and CREATE were published, suggesting that lower hemoglobins are safer than those exceeding approximately $12.6 \mathrm{~g}$ per $\mathrm{dL}$. Consequent to the U.S. Food and Drug Administration's requirement for a black box warning, the KDOQI work group reconvened and published revised guidelines in September 2007 stating, "In the opinion of the Work Group, in dialysis and non-dialysis patients with CKD receiving ESA therapy, the selected hemoglobin target should generally be in the range of 11 to 12 g per dL." 19

\section{Bone Disease Parameters}

KDOQI has also established targets for serum phosphorous, corrected calcium, the calcium-phosphorous product (a multiplication product of phosphorous and calcium levels), and intact parathyroid hormone in patients with CKD (Table 3). Once calcium-phosphorous product exceeds the reference range of between 40 and $45 \mathrm{mg}^{2}$ per $\mathrm{dL}^{2}$, the relative risk of death increases. Patients with secondary hyperparathyroidism or bone and mineral metabolism abnormalities often have bone pain, fractures, and joint pain and swelling. Their soft tissues may start to calcify and muscle weakness may occur. Pruritis, exacerbation or worsening of left ventricular hypertrophy, or worsening of anemia can also occur.

\section{Dyslipidemia}

Dyslipidemia is common in patients with CKD, and the lipid profile varies widely depending on the level of kidney function and the degree of proteinuria. All stages of CKD are considered a coronary heart disease (CHD) risk equivalent (similar to diabetes mellitus); therefore, all patients with CKD should be considered in the highest risk group for CHD. The common pattern of late-stage CKD includes hypertriglyceridemia, low or normal levels of low-density lipoprotein (LDL), low lipoprotein (a), and low high-density lipoprotein (HDL). KDOQI recommends initiating treatment when triglycerides exceed $>500 \mathrm{mg}$ per dL, LDL is $>100 \mathrm{mg}$ per dL, non-HDL > $130 \mathrm{mg}$ per dL, or HDL falls $<40 \mathrm{mg}$ per $\mathrm{dL}{ }^{5}$

Generally, HMG-CoA reductase agents (statins) are used to lower LDL; fibrates, including fenofibrates, are used to lower triglycerides; and niacin is used to increase HDL. In the CKD population, HMG-CoA reductase agents (statins) are preferred, with gemfibrozil and niacin used periodically. The complete NKF algorithm for treating dyslipidemia in CKD is available at www. kidney.org/professionals/kdoqi/guidelines_lipids/iii.htm\#Fig7. 


\section{Smoking}

In the CKD population, smoking confers a dose-dependent risk for CKD progression, with diabetic women at particular risk. After 20 years of smoking, males have 2.5 times the risk of $\mathrm{CKD}$, and women have 2.9 times greater risk than nonsmokers. ${ }^{20}$ Smoking represents one of the modifiable risk factors to improve patient outcomes in the CKD patient (Table 4).

\section{Progress Report}

Using Table 4 as a guide of optimal patient management, most patients are not managed to goal and there are many gaps to achieving optimal care. Among diabetics, only $7 \%$ of patients achieve their goals of Alc $<7$, a blood pressure $<130 / 80 \mathrm{~mm} \mathrm{Hg}$, and total cholesterol $<200 \mathrm{mg}$ per dL. ${ }^{21}$ Ninety-three percent of all patients have 1 or more of these risk factors for CKD development. One in 3 diabetics has hypertension, 1 in 2 has hyperlipidemia, and 1 in 6 is a smoker. ${ }^{21}$

ACEIs and ARBs are the cornerstone of hypertension therapy. They have been proven to slow kidney and CVD progression in diabetic populations specifically. Yet depending on the datasets employed to measure progress (e.g., National Health and Nutrition Examination Survey [NHANES] III or NHANES from 1999 to 2002), only 35\% to $37 \%$ of patients who should be prescribed an ACEI or an ARB (patients with diabetes, hypertension, or heart failure) actually receive these renal protective therapies. Underuse of ACEIs and ARBs is also an area that can be improved. ${ }^{22}$

Patients with comorbid CKD and diabetes should be taking a glucose-lowering agent (e.g., insulin, thiazolidinediones, secretagogues, or metformin). NHANES has been used for decades to assess nutritional status in the United States. Datasets from NHANES III (1988 to 1994) or NHANES (1999 to 2002) show clear differences in drug regimens between the CKD and non-CKD populations. For example, metformin use reported in NHANES is substantially less in CKD patients than in non-CKD patients ( $21 \%$ vs. $34 \%$ ), which may be attributed to metformin's propensity to cause lactic acidosis CKD. The manufacturer has recently tightened its recommendation for use of metformin in patients with kidney disease and states that patients whose serum creatinine concentrations exceed the upper limit of normal should not take metformin.

The United States Renal Data System (USRDS) 2007 Medstat dataset compares CKD and ESRD patients' adherence with a variety of drug regimens: ACEIs, ARBs, beta-blockers, statins, and secretagogues. Both CKD and ESRD populations show medication adherence rates of about $80 \%$ during the first 6 to 12 months after initiation. However, over the course of 2 years, medication adherence rates decrease steadily to $50 \%$. Patients who are in ESRD take, on average, 10 to 12 medications; CKD patients take 6 to 8 medications. Numerous factors contribute to nonadherence, but the number and timing of medications

\begin{tabular}{l|c|c}
\hline \multicolumn{1}{c}{ TABLE 3 } & \multicolumn{2}{c}{ KDOQl Targets } \\
for Bone Disease Parameters \\
\hline Parameter & \multicolumn{2}{c}{ Target } \\
\hline Serum P (mg per dL) & CKD Stages 3-4 & CKD Stage 5 \\
\hline Corrected serum Ca (mg per dL) & $\begin{array}{c}\text { Normal range for } \\
\text { laboratory used }\end{array}$ & $8.4-9.5$ \\
\hline Cax P product $\left(\mathrm{mg}^{2}\right.$ per dL $\left.\mathrm{dL}^{2}\right)$ & $<55$ & $<55$ \\
\hline $\begin{array}{l}\text { Intact parathyroid hormone } \\
\text { (pg per mL) }\end{array}$ & $\begin{array}{c}\text { Stage 3: 35-70 } \\
\text { Stage 4: 70-110 }\end{array}$ & $150-300$ \\
\hline
\end{tabular}

Adapted from K/DOQI Clinical Practice Guidelines for Bone Metabolism and Disease in Chronic Kidney Disease. Available at: www.kidney.org/professionals/ KDOQI/guidelines_bone/guide1.htm\#table14.

$\mathrm{Ca}=$ calcium; $\mathrm{CKD}=$ chronic kidney disease KDOQI=Kidney Disease Outcomes Quality Initiative; $P=$ phosphorus.

\section{TABLE $4 \longdiv { 1 0 \text { Steps to Success } }$}

\begin{tabular}{l|l}
\hline 1. & Hypertension control-130/80 mmHg \\
\hline 2. & Hemoglobin target-11-12 g per dL \\
\hline 3. & Glucose control_Alc $<7$ \\
\hline 4. & Lipid control_LDL-C $<100 \mathrm{mg}$ per dL, HDL-C $>40 \mathrm{mg}$ per dL \\
\hline 5. & Smoking cessation \\
\hline 6. & Aspirin + beta-blocker use post-myocardial infarction \\
\hline 7. & ACEI or ARB therapy \\
\hline 8. & Diet \\
\hline 9. & Exercise \\
\hline 10. & Weight control \\
\hline
\end{tabular}

$A C E I=$ angiotensin-converting enzyme inhibitor; $A R B=$ angiotensin II receptor blocker; HDL-C=high-density lipoprotein cholesterol; LDL-C=low-density lipoprotein cholesterol.

and the duration of treatment are 2 reasons that can decrease adherence significantly.

\section{Summary}

CKD is quite common but is often unrecognized and undertreated. Appropriate screening can identify patients at risk and facilitate early treatment for these patients. One program that has successfully screened patients and referred them for treatment is the NKF's KEEP. To date, more than 90,000 patients have been screened through KEEP, thanks in part to professional volunteers and a broad advertising campaign. When patients are identified as having $C K D$, this program helps link them with appropriate health care. Patients' specific health care plans should be guided by the NKF's KDOQI clinical practice guidelines, which recommend optimal management therapies for a variety of comorbid conditions to reduce complications in these patients. Early identification and aggressive treatment can prevent progression to ESRD. 


\section{DISCLOSURES}

Author Harold J. Manley discloses no potential bias or conflict of interest relating to this article.

\section{REFERENCES}

1. National Kidney Foundation. Kidney Early Evaluation Program. Available at: www.kidney.org/news/keep/KEEPabout.cfm. Accessed August 25, 2007.

2. The United States Renal Data System. The United States Renal Data System Annual Data Report 2006. Available at: www.usrds.org/adr_2006.htm. Accessed August 25, 2007.

3. Bailie GR, Eisele G, Liu L, et al. Patterns of medication use in the RRI-CKD study: focus on medications with cardiovascular effects. Nephrol Dial Transplant. 2005;20:1110-15.

4. Manley HJ, Garvin CG, Drayer DK, et al. Medication prescribing patterns in ambulatory hemodialysis patients: comparisons of USRDS to a large not-for-profit dialysis provider. Nephrol Dial Transplant. 2004;19:1842-48.

5. National Kidney Foundation. KDOQI. Am J Kidney Dis. 2006;47(suppl 3):S1-S145.

6. Go AS, Chertow GM, Fan D, McCulloch CE, Hsu CY. Chronic kidney disease and the risks of death, cardiovascular events, and hospitalization N Engl J Med. 2004;351:1296-305.

7. Sarnak MJ, Levey AS. Epidemiology of cardiac disease in dialysis patients. Semin Dial. 1999;12:69-76.

8. Bakris GL, Williams M, Dworkin L, et al. Preserving renal function in adults with hypertension and diabetes: a consensus approach. National Kidney Foundation Hypertension and Diabetes Executive Committees Working Group. Am J Kidney Dis. 2000;36:646-61.

9. National Heart, Lung, and Blood Institute. The Seventh Report of the Joint National Committee on Prevention, Detection, Evaluation, and Treatment of High Blood Pressure (JNC 7). Available at: www.nhlbi.nih.gov/guidelines/ hypertension/. Accessed September 13, 2007.

10. Lewis EJ, Hunsicker LG, Clarke WR, et al.; Collaborative Study Group. Renoprotective effect of the angiotensin-receptor antagonist irbesartan in patients with nephropathy due to type 2 diabetes. N Engl J Med. 2001;345: 851-60
11. Gaede P, Vedel P, Larsen N, Jensen GV, Parving HH, Pedersen O. Multifactorial intervention and cardiovascular disease in patients with type 2 diabetes. N Engl J Med. 2003;348:383-93.

12. Keane WF, Brenner BM, de Zeeuw D, et al.; RENAAL Study Investigators, The risk of developing end-stage renal disease in patients with type 2 diabetes and nephropathy: the RENAAL study. Kidney Int. 2003;63:1499-507.

13. Erslev AJ. Erythropoietin. N Engl J Med. 1991;324:1339-44.

14. National Kidney Foundation. National Kidney Foundation releases preliminary anemia guideline update. April 12, 2007. Available at: www.kidney. org/news/newsroom/newsitem.cfm?id=380. Accessed November 20, 2007.

15. Kapur A, Malik IS, Bagger JP, et al. The Coronary Artery Revascularisation in Diabetes (CARDia) trial: background, aims, and design. Am Heart J. 2005;149:13-19.

16. Singh AK, Szczech L, Tang KL, et al.; CHOIR Investigators. Correction of anemia with epoetin alfa in chronic kidney disease. N Engl J Med. 2006; 355:2085-98.

17. Drueke TB, Locatelli F, Clyne N, et al.; CREATE Investigators. Normalization of hemoglobin level in patients with chronic kidney disease and anemia. N Engl J Med. 2006;355:2071-84.

18. Besarab A, Bolton WK, Browne JK, et al. The effects of normal as compared with low hematocrit values in patients with cardiac disease who are receiving hemodialysis and epoetin. N Engl J Med. 1998;339:584-90.

19. KDOQI. KDOQI clinical practice guidelines and clinical practice recommendations for anemia in chronic kidney disease: 2007 update of hemoglobin target. Am J Kidney Dis. 2007;50:471-530.

20. Ejerblad E, Fored CM, Lindblad P, et al. Association between smoking and chronic renal failure in a nationwide population-based case-control study. J Am Soc Nephrol. 2004;15:2178-85.

21. Imperatore G, Cadwell BL, Geiss L, et al. Thirty-year trends in cardiovascular risk factor levels among U.S. adults with diabetes: National Health and Nutrition Examination Surveys, 1971-2000. Am J Epidemiol. 2004;160:531-39.

22. Nissenson AR, Collins AJ, Hurley J, Petersen H, Pereira BJ, Steinberg EP. Opportunities for improving the care of patients with chronic renal insufficiency: current practice patterns. J Am Soc Nephrol. 2001;12:1713-20. 